\title{
VALUES ATTRIBUTES FOR THE SELECTION STRATEGY ON HOSPITALITY MARKET
}

\author{
Janusz Kroik ${ }^{a}$, Adam Świda \\ Department of Computer Science and Management, \\ Wroclaw University of Technology, Wrocław, Poland, \\ ae-mail: janusz.kroik@pwr.edu.pl \\ be-mail: adam.swida@pwr.edu.pl
}

\begin{abstract}
Purpose: Main purpose of the article is presentation the empirical researches on Wroclaw's hospitality market.

Methodology/approach: The researches cover Economy class hotels and focused on VABS (VABS - Value Attribute Based Strategy). The study was limited to three-star hotels (economy class) and the same reason of to arrival (tourism) in order to preserve the homogeneity of customer group economic class. Moreover opinions on Guest extracted from hotels located in the city centre. Of the 22 three-star hotels were selected 17 for testing.

The studies gathered information from more than 120 customers choosing 90 , which stay in the hotel were combined to the tourist destination. In the study participated 25 managers of hotels.

Findings: The selected segment results of the hospitality market in Wroclaw, confirmed the existence of several value attributes. These are the attributes that allow us to maintain a not only relatively higher price of economy class hotels but overall competition strategies. Partly there are also confirmed the results obtained in other studies market hospital.

Implications: In the case of another testing researches we recommended - 200 customers - sample size for verifying the results.

Originality/value of the paper: Original empirical researches and results have always utility value. Identifying important competition issues for hospitality market could help in formulating the local development strategies.
\end{abstract}

Keywords: Strategy, hospitality, value attributes, competitiveness, advantage, distinguish

Paper type: Research paper

\section{Introduction}

Phen omenon called the commoditisation of goods and services is a direct manifestation of uncompromising market rivalry (D’Aveni and Piłat, 2010). The customers see the price as an only condition of their decisions and the company (seller) reacts adequately to the working activity. Products and services in the 
VALUES ATTRIBUTES FOR THE SELECTION STRATEGY

Janusz Kroik Adam Świda

eyes of customers lose its uniqueness, the differences between brands disappear, and the only feature that allows them to distinguish from one another is the price. Therefore fighting for their existence the company competes in tenders of various cost benefits. As a result, it causes lowering of the quality of products and services that are derived from cost reduction and bring to market products or services of lower quality and lower price, for example through discount stores or making its own trade network. There is also to offer an extensive palette of varieties product/service little different from the basic (of the original) standard. Elected to the empirical analysis of the problem of clipping actually refers to the hospitality market in Wroclaw in Economy Class characterized by high intensity of competition and ability to make well packaged in a variety of innovative ideas, demonstrating their willingness to develop varieties of the product/service and their escalation.

Market of hotel services includes a wide set of tools (requirements and constraints), which protect it from loss of quality standards, e.g. in the form of international standards forcing a certain level and scope of basic and additional services. Naturally it blocks the phenomenon of commoditisation, particularly in terms of reducing the quality (called deterioration trap) of basic service.

A special role is counter to the strategies of based on the attribute of value (VABS -Value Attribute Based Strategy). Their prerequisite are: getting the benefits of the customer associated with the reduction of its cost, the price charged to support the continued circulation, improving the quality (Ruskin and Brown, 2009).

The basic premises are exposing these elements that offer value to the recipient, who do not treat price as the highest priority, emphasizing other features recognized and accepted by the customer (Kubisiak et al., 2013). The fulfilment of this suggestion requires a diagnosis of features and assessing their relevance to the customer.

A set of factors affecting the prices in the hotel is extremely large due to the variety of facilities and complementary services possible to be "packed" in the offer. This does not mean that each factor may be a strategic premise. Most of them are only a necessary standard.

The article assumes that the VABS focus from one side only on those aspects for which customers are willing to make an additional "sacrifice" (benefitted from the terms used e.g. (Simon, 1996)) on their behalf, and on the other hand, they are recognized and accepted by the managers of hotels. This means that there is, thanks to these attributes, the chance to maintain not only higher prices but the formulation of the overall strategy to compete. Specific aim of the article is confirmation (by own researches) that value attributes for hotel's clients and managers are similar. The fact enables creating proper strategy.

Literature review allowed to list more than 40 potential factors, and only a few, as mentioned, will become attributes values. 
The researchers, the so-recognized strategy VABS, used their own customer reviews in the selected segment of hotel services. The data allowed using the analysis of factors and identifying the most important of them. The data allowed using the analysis of factors and identifying the most important of them-potential

VALUES ATTRIBUTES FOR THE SELECTION STRATEGY Janusz Kroik Adam Świda attributes of the strategy. The results were related to the gathered parallel views of hospitality managers of economy Class . The study was conducted in June 2013.

There are three non-market approaches to pricing in the hotel industry: cost, pocket calculation rule-of-thumb formulas and Hubbard's. The attitudinal market approaches for hotel services are determined, thoroughly analyzing occurrence and situations on the hotel market in the defined local area. Collecting information about competing hotels, analyzing the basic service charges and additional information. On this basis determines the price accepted by the market.

In practice (on western European markets), the defined acceptable rates of various types are used for discounts and price incentive so as to obtain a specific sales effect, particularly when it seeks to strongly of coating costs incurred. The price is varied according to the different circumstances that encourage customers to use the services of a hotel. It is independent of the conditions situating the hotels to a specific category (quality of service) and coupled prices with them.

\section{Prices differentiation in the hotel services - strategic and tactical choices}

Examining the conditions of affecting the level of acceptable prices in the hotel are carried out successively (this type of research they are led on currently with support of internet technique - according to consulting firm Nielsen/NetRatings opinion, informations placed into data basis by individuals, are noticed as more honest source than it, which is placed by touristic portals or on www pages of hotels). Research indicated the emergence of non-standard situations in which - under the assumption that customers are sensitive of hotels prices and made a radical price reductions (about 30\%) are not satisfied at the same time with the increase occupancy rates. It turned out that the price elasticity is less than one, so the revenue from room per night fell. At the same time there was also the opposite case, when the economy hotels have raised prices slightly (about 5\%) and their revenue per room per night increased by about 1.5\% (Gutowski, 2010).

Overall, the set of conditions which are taken into account the offer price hotels are (Panasiuk and Szostak, 2009):

- aim to use the hotel: sightseeing, vacation, business meeting, education;

- additional benefits offered by the hotel: Packed Beds, extra gratis night legislative, loyalty cards, discounts on various services;

- target group: seniors, camps and group, family, individual customers (the creation of various special offers tailored to the needs of the group, cooperation with relevant organizations, whose services will be interested 
which you do not have to pay. This method is to examine the relationship between the functions of one variable, and a group of other subsidiaries. Hedonic price analysis assumes that the price of the product or service is a function of packet factors - the facilities offered to the guests. During the study it was analyzed

VALUES ATTRIBUTES FOR THE SELECTION STRATEGY

Janusz Kroik Adam Świda the rates of rooms 1 and 2 - personal. Features that were considered in this study include; belongs to the hotel chain, has a mini - bar, swimming pool, free parking space for hotel guests, no restaurant, and no room service, what is the proximity distance to the train station. Experimentally determined coefficients of seemingly unrelated regression under certain circumstances can be considered as a percentage change of the independent variable (the price one-and two-person). It was proved that night in the hotel of the network in single - seated was up to $15 \%$ more expensive than in the hotel of the same standard does not belong to the network. Single rooms having mini-bars were more expensive by $51 \%$ than those who do not have that facility. Prices in hotels with free parking were more expensive by up to $19 \%$ of those that do not provide such a possibility. In contrast, it was surprised that in these hotels, which offered room service, the prices were higher by $12 \%$ compared to the hotels do not offer this service. The features that do not affect of the price are: a swimming pool and a restaurant. In another study, on date from New York, which were empirically suggested that the quality and location are important determinants of room prices but these attributes can be varied depending on the segment hotel (Zhang et al., 2011).

\section{Value Attributes for the choice of strategy - own research}

Hospitality market in Wroclaw has become a highly competitive market. On the supply side during the period of over 20 years it was made a lot of investments and modernization. According to the state at the end of 2013 in Wroclaw there were registered 169 hotels and hotels with websites; including 22 three star hotels, 13 four-star and five-star 5. Hotel base is sufficient to support normal and increased needs which are reported by the market.

\subsection{Assumptions of research}

The study was limited to three-star hotels (economy class) and the same reason of to arrival (tourism) in order to preserve the homogeneity of the group of customer's acids economic class. Moreover opinions on Guest extracted from hotels located in the city centre. Of the 22 three-star hotels were selected 17 for testing. In the period of collecting the feedback, it has been observed, as a background pricing, the price level for one-and two - person rooms in selected hotels, without consideration for the so-called discounts ending of occupancy or other circumstances. Differences in offered prices were stable and significant (between the lowest price and the highest the difference was over $100 \%$ ). Most offers fluctuated at level of 50\% higher than the lowest price. 
VALUES ATTRIBUTES FOR THE SELECTION STRATEGY

Janusz Kroik Adam Świda
The results of analysis of the factors were referenced to the managers of these hotels in order to check compliance of their assessment of the views of customers. The average number of visits by respondents hotels guests is more than 4 times a year. To evaluate the factors (attributes) for the 5 - point scale was used selection effect on the price, where: 1 - no impact, 2 probably little impact, 3 - little impact, 4 - moderate impact, 5 - strong influence.

It was assumed that obtaining the opinion should refer to the widest possible range of factors that potentially could affect the willingness to accept a higher/ lower price for the hotel service on the converted price. The 43 factors are separated and divided into three groups A, B, C.

A. Internal factors - listed 29 factors;

B. External factors - listed 10 factors;

C. Techniques approach to differentiate pricing by the hotel - listed 4 factors.

The studies were obtaine d information from more than 120 customers choosing 90, which stay in the hotel were combined to the tourist destination. The application of factor analysis condition was fulfilled ( 2 times more than the number of selected factors, preferably a better 5 times). For processing the data was used a standard software package SPSP.

In order to determine the attributes of the strategy extracted factors should be accepted by the managers of these hotels. In the study participated 25 managers of hotels (one or two people from the hotel).

\subsection{Selection of potential attributes for customer-factor analysis}

1. Remove the variables of low value. Variables removed (average below 3 ) are:

The image of the hotel (mean 1.9, group A, No. 1 in group); target group (2.9, A, No. 5); Location of equipment in the room (2.9, A, No. 12); Elevator (2.1, A No. 13); belong to the chain hotels (2.6, A, No. 19); Conference room (2.2, A, No. 26); Childcare (1.1, A, No. 27); Cosmetic (2.3, A, No. 29); environment (2.7, B, No. 3); Distance from the railway station (2.8, B, No. 6); Distance from the airport (2.9, B, No. 7); distance from the access road (2.9, B, No. 8); Psychology (2.8, B, No. 10); Price on uneven ends (2.9, C, No. 3$)$.

2. Elimination of the factors on the basis of the inverse correlation matrix (the value of the coefficient of less than 0.5 eliminates the given variable).

In this case the factors are eliminated, The hotel staff (A, No. 9); Hotel Class (A, No. 10); Appearance and equipment rooms (A, No. 11); Internet access (A, No. 15); hygiene (A, No. 16); Condition of equipment (A, No. 17); access to additional features (A, No. 18); parking for hotel guests (A, No. 20); Free parking for hotel guests (A, No. 21); Catering (A, No. 22); meals included (A, No. 24); Place of entertainment (A, No. 28). 
3. Elimination of the factors on the basis of the total variance.

The factors of the intrinsic value of greater than one were proposed further reduction variables. There were nine. Removal of specific 8 factors from the set of 17 factors (to level nine) took place through a matrix model for the condition that each of the variables was loading only one component. The final matrix loaded by one component (1.000) is given below.

\begin{tabular}{|c|c|c|c|c|c|c|c|c|c|}
\hline & \multicolumn{9}{|c|}{ Compound } \\
\hline & 1 & 2 & 3 & 4 & 5 & 6 & 7 & 8 & 9 \\
\hline Room service & 1.000 & & & & & & & & \\
\hline Place of purchase & & 1.000 & & & & & & & \\
\hline Seasonality & & & 1.000 & & & & & & \\
\hline Additional amenities & & & & 1.000 & & & & & \\
\hline Number of beds & & & & & 1.000 & & & & \\
\hline Culture & & & & & & 1.000 & & & \\
\hline Location & & & & & & & 1.000 & & \\
\hline Cultural places & & & & & & & & -1.000 & \\
\hline $\begin{array}{l}\text { Time and condition of } \\
\text { payment }\end{array}$ & & & & & & & & & 1.000 \\
\hline
\end{tabular}

Method of distinguish $\mathrm{m}$ a in compounds. Rotation method - Kaiser's normalisation.

Screenshot of the final iteration. Potential attributes in the matrix; Room service (group A, No. 25 in the set); Place of purchase the services (A, No. 7); Seasonality of demand (A, No. 4); Additional room amenities (A, No. 14); Number of beds (A, No. 23); Culture - traditions, holidays in the region (B, No. 9); Location in the metropolitan region, (B, No. 2); Cultural places - influence on distance of cultural places (B, No. 4); The time and conditions of payment (A, No. 8).

Eight attributes were removed; Additional benefits offered by the hotel (A, No. 2); Discount comparative (C, No. 4); size of the group (A, No. 6); Proportionality of money (C, No. 1); distance from the center (B, No. 5); price stability (C, No. 2); and length of stay (A, No. 3). $\begin{array}{r}\text { VALUES ATTRIBUTES } \\ \text { FOR THE SELECTION } \\ \text { STRATEGY } \\ \hline \begin{array}{r}\text { Janusz Kroik } \\ \text { Adam Świda }\end{array}\end{array}$ 
VALUES ATTRIBUTES FOR THE SELECTION STRATEGY

Janusz Kroik Adam Świda

\subsection{The imposition of the manager views - value attributes for selection the strategy}

Many factors eliminated in the analysis confirms that standardization takes guests' expectations and this may not be a prerequisite for VBP strategy. These include Appearance and equipment rooms (A, No. 11); Internet access (A, No. 15); hygiene (A, No. 16); technical condition of equipment (A, No. 17); access to additional features (A, No. 18); Parking for hotel guests (A, No. 20); Free parking for hotel guests (A, No. 21), etc. To determine the attributes of the strategy extracted factors should be according to the assumptions and accepted by the managers of hotels (It operate in analysis average arithmetic and subsidiary structure of answer of manager. It accept, that at least it makes it possible in numerical scale for employment average 3.67 recognition of factor important premise over (2/3) to VBP, (+) or (+/-). Result did not allow as low premise of value in numerical scale acceptance for 2.34 below (1/3) even VBP. Possible former pricing of factor in range remaining as average or low, (-/+) or (-)).

1. Room (room service), (group A, No. 25 in the set).

It was noted that the form of individual attention, being available to the customer is a factor entitling the holder to a change in price. Managers (average 3.72 ) agreed and $80 \%$ of them indicated the existence of this influence, and $64 \%$ felt that the effect is at least moderate. This factor, in light of the results of other studies can be considered as value attribute for the strategy.

2. Place of purchase the services (Internet, in person, travel agency, etc.), (A, No. 7).

The positive assessment of this factor by customers may have affected contexts such as shopping portals Group or the existence of aggregate sites offer all the hotels. Managers sentence was enough "exploded" (mean 2.76). The largest group of responses $-32 \%$ chose a moderate impact. This factor cannot be used as value attribute of strategy VABS.

\section{Seasonality of demand (A, No. 4).}

It is quite obvious impact factor score and hotel managers (mean 4.2, 52\% range of options decisive influence) were consistent. From the point of view of the occurrence of commoditisation there are two possible interpretations. First are high compliance expectations and the rationale of decision-making leads to natural changes in the prices of hotel services depending on the season and time of seasonal events, and thus can capture the tendency to seek opportunity pricing in the market competition. On the other hand, it appears pressure (booster) demand at certain periods of stability can stabilize prices at a higher level. This factor can be used as value attribute of strategy VABS but with the threat of "dangerous rivalry". 
4. Additional room amenities (hairdryer, iron, TV, minibar, air conditioning, etc.) (A, No. 14).

The wide range of the type of equipment made it possible to identify an extra acceptable value for their disposal. This view was also consistent with the opinions of managers (average 3.98). The equipment can have a positive value attributes (use the VABS), but this would require further research on the type of equipment.

\section{Number of beds (A, No. 23).}

Respondents accepted the assumption that, for economy class hotel, a larger number of rooms occupied with the corresponding results in the reduction of the shares of fixed costs in the price and thus the potential for its reduction. Managers, probably from/by the practice, they were quite careful in articulating the high impact of this factor on the price (average 3.00). Number of rooms might be administrate, under certain conditions contribute to generating a tendency to increase turnover with price reductions, with specific protection in the potential margin value to cover the costs. It is therefore that may determine the use of price war. This factor cannot be used as value attribute of the strategy.

\section{Culture - traditions, holidays in the region (B, No. 9).}

Opinions managers were balanced (mean 2.70, the highest option - moderate impact is $28 \%$ ). From the point of view of the occurrence of commoditisation it can be seen by two conditions of interpretation. The first indicates the stability of customer expectations in delivering value for which they decided to stay in a hotel, the other resulting from the possible existence of many hotels offering similar experiences and values. Rather, it should not be value attribute for the choice of strategy VABS.

7. Location in the metropolitan region - the distance from the important to the customer places; peripherals, center, a local resident benefit (B, No. 2).

The location of the hotel in the region rated as key to shaping (from the perspective of managers - average 3.80, up $64 \%$ from the evaluation of a definite effect) and acceptance (from the perspective of clients) high prices. Location has its advantages and disadvantages, for which the customer, choosing a hotel, you will be willing "to make a greater sacrifice". On the periphery customers will take into silence, calm, beautiful landscapes, nature and perhaps also the closeness of culture. In the centre of the simplicity of communication, the availability of attractions and places of cultural interest. Managers can assume the higher prices knowing the strengths and predictable environment the demand based on data from previous periods. It can be an important value attributes for decision-making in the strategy. 
VALUES ATTRIBUTES FOR THE SELECTION STRATEGY

Janusz Kroik Adam Świda

Table 2.

Synthetic evaluation value attributes for selection strategy
8. Cultural places - influence on distance of cultural places; monuments, museums, theatres, etc., (B, No. 4).

This factor is perceived by customers as an important prerequisite for the price offer, especially when the destination of your stay, it is not surprising. Managers also recognized it as an important (mean 3.8, and $52 \%$ indicated a strong impact on the price). This means that value attributes is created around the hotel features location based on providing proximity to places joined the objectives of the guests stay.

\section{The time and conditions of payment (A, No. 8).}

For managers the time and form of payment was not an important prerequisite for the pricing of the service provided. It was the least valued of 9 analyzed factors (average 2.50). However, for customer convenience can mean the transaction and also assured reservation. The conditions of payment you can also understand various types of vouchers or coupons that you can buy or get and thus reduce the final amount of the bill. Time in this factor could be combined in many ways such as the payment on account or the full amount in advance and the simultaneous discount (e.g. by paying a bed within a week of booking, receive a $10 \%$ discount), the possibility of payment for the stay on. Check what is beneficial for the client does not have at the moment free resources and can be a risk for the hotel. Managers caution indicates that the operation of this factor in price formation and finding advantages in this respect is dangerous.

When applying the results of both groups of respondents from the point of view of the conditions for the strategy AVBS, synthetic evaluation is given in the following table.

\begin{tabular}{|c|c|}
\hline Attributes & $\begin{array}{l}\text { Indications for the strategy } \\
\text { (+ positive, }- \text { negative })\end{array}$ \\
\hline 1 Room (room service), (group A, No. 25 in the set) & $(+)$ \\
\hline $\begin{array}{l}2 \text { Place of purchase services (Internet, in person, travel } \\
\text { agency, etc.), (A, No. 7) }\end{array}$ & $(-)$ \\
\hline 3. Seasonality demand (A, No. 4) & $(+/-)$ with the option of easy imitation \\
\hline 4. Additional room equipment & $(+)$ \\
\hline 5. Number of beds (A, No. 23) & (-) appealing to " fight " the price \\
\hline 6. Culture - traditions, holidays in the region (B, No. 9) & $(-/+)$ probably not \\
\hline $\begin{array}{l}\text { 7. Location in the metropolitan region - the distance } \\
\text { from the important to the customer places; periphery, } \\
\text { center, a local resident benefit (B, No. 2) }\end{array}$ & $(+)$ \\
\hline $\begin{array}{l}\text { 8. Culture places - impact distance of cultural sites; } \\
\text { monuments, museums, theatres, etc., (B, No. 4) }\end{array}$ & $(+)$ \\
\hline 9. The time and conditions of payment (A, No. 8) & $(-)$ \\
\hline
\end{tabular}




\section{Conclusions}

The results of the selected segment of the hospitality market in Wroclaw, confirmed the existence of several value attributes. These are the attributes that allow you to maintain a not only relatively higher price of economy class hotels but overall competition strategies. Partly there are also confirmed the results obtained in other studies market hospital - for example results achieved and published by Bayomi (Bayomi, 2013). This applies to the location of high importance and use. Closer analysis shows that no less suggest the existence of up to five factors (indicated in the statement as + and $+/-$ ), which could give rise to the VABS strategy for third prerequisite mentioned at introduction of Ruskin-Brown publication (RuskinBrown, 2009).

It was observed extreme price offers facilities 3 stars in the centre of Wroclaw stable and differed significantly by $100 \%$. However, the concerned hotel offer the lowest operating since many decades and not passing thorough revitalization. This confirms that the less comfortable aspects of equipment and infrastructure as well as individualized service results in favor of lower prices in accordance with the relation price - quality, and this is not the effect of a price war but understanding existing conditions. It can be assumed that - eliminating the extreme case differences in the other offers hotels of $30 \%$ were the result of a sense of fulfilling the expectations of customers who attach importance to these - even five attribute values identified in the research.

Rating created applications is cautious. In the case of testing the recommended sample size (approximately 200 customers) and confirm the results, they will be able to have even greater utility. In the practice of the budget hotels suggested the possibility of a well-known model in the airline reservation on the principle; Buy earlier with a lower price. This model is not a simple, one-dimensional.

At the end, we should refer to the general results of the researches. According to this research, Wroclaw has enough hotels to serve touristic rush. The valid elements are: increasing competitiveness via personnel development and obtaining talented workers, respectively.

\section{References}

Bayoumi, A. E. M., Saleh, M., Atiya, A. F., Aziz, H. A. (2013), ’Dynamic pricing for hotel revenue management using price multipliers", Journal of Revenue and Pricing Management, Vol. 12 No. 3, pp. 271-285. DOI: http://dx.doi.org/10.1057/rpm.2012.44

D’Aveni, R., Piłat, K. (2010), "Utowarowienie - cichy zabójca zysków”, Harvard Business Review, No. 4 /2010, available at: http://www.hbrp.pl/news.php?id=390\&str=1, (accessed 15 December 2014).

Gutowski, M. (2010), "Jak ustalać ceny w czasie kryzysu", Hospitality Kwartalnik menedżerów hotelarstwa, No. 2/2010, pp. 19-24.

Kubisiak, P., Posiadło, J., Prokurant, S. Rosołoniec, A., Zibert, B. (2013), ”Czy istnieje
VALUES ATTRIBUTES FOR THE SELECTION STRATEGY

Janusz Kroik Adam Świda 
VALUES ATTRIBUTES FOR THE SELECTION STRATEGY

Janusz Kroik

Adam Świda alternatywa dla rywalizacji cenowej?", Harvard Business Review, No. 3/2013, available at: http://www.hbrp.pl/biblioteka/art.php?id=6096\&t=czy-istnieje-alternatywadla-rywalizacji-cenowej, (accessed 15 December 2014).

Panasiuk, A., Szostak, D. (2009), Hotelarstwo. Ustugi - eksploatacja - zarzqdzanie, PWN, Warszawa.

Ruskin-Brown, I. (2009), Skuteczna polityka cenowa, Oficyna Wolters Kluwer business, Warszawa.

Simon, H. (1996), Zarządzanie cenami, PWE, Warszawa.

Thrane, C. (2006), "Examining the determinants of room rates for hotels in capital cities: The Oslo experience", Journal of Revenue and Pricing Management, Vol. 5 No. 4, pp. 315-323.

Zhang, Z., Ye, Q., Law, R. (2011), ’Determinants of Hotel Room Price: An Exploration of Travelers' Hierarchy of Accommodation Needs", International Journal of Contemporary Hospitality Management, Vol. 23 No. 7, pp. 972-981. DOI: http://dx.doi. org/10.1108/09596111111167551 